\title{
Select Liquefaction Case Histories from the 2010-2011 Canterbury Earthquake Sequence
}

\author{
Russell A. Green, ${ }^{\text {a) }}$ M.Eeri, Misko Cubrinovski, ${ }^{\text {b) }}$ Brady Cox,${ }^{\text {c) }}$ M.Eeri, \\ Clint Wood, ${ }^{\mathrm{c})}$ S.M.EERI, Liam Wotherspoon, ${ }^{\mathrm{d})}$ M.EERI, \\ Brendon Bradley, ${ }^{\text {b) }}$ M.EERI, and Brett Maurer, ${ }^{\text {a) }}$ M.EERI
}

The 2010-2011 Canterbury earthquake sequence began with the 4 September 2010, $\mathrm{M}_{\mathrm{w}} 7.1$ Darfield earthquake and includes up to ten events that induced liquefaction. Most notably, widespread liquefaction was induced by the Darfield and $\mathrm{M}_{\mathrm{w}} 6.2$ Christchurch earthquakes. The combination of well-documented liquefaction response during multiple events, densely recorded ground motions for the events, and detailed subsurface characterization provides an unprecedented opportunity to add well-documented case histories to the liquefaction database. This paper presents and applies 50 high-quality cone penetration test (CPT) liquefaction case histories to evaluate three commonly used, deterministic, CPT-based simplified liquefaction evaluation procedures. While all the procedures predicted the majority of the cases correctly, the procedure proposed by Idriss and Boulanger (2008) results in the lowest error index for the case histories analyzed, thus indicating better predictions of the observed liquefaction response. [DOI: 10.1193/030713EQS066M]

\section{INTRODUCTION}

The objective of this study is to present high-quality liquefaction case histories from the 2010-2011 Canterbury earthquake sequence and to use these case histories to evaluate three commonly used, deterministic, cone penetration test (CPT) based simplified liquefaction evaluation procedures. The 2010-2011 Canterbury earthquake sequence began with the 4 September $2010 M_{w} 7.1$ Darfield earthquake and included up to ten events that induced liquefaction (Quigley et al. 2013). However, most notably, widespread liquefaction was induced by the $M_{w} 7.1,4$ September 2010 Darfield and the $M_{w} 6.2,22$ February 2011 Christchurch earthquakes. The ground motions from these events were recorded across Christchurch and its environs by a dense network of strong motion stations (e.g., Cousins and McVerry 2010, Bradley and Cubrinovski 2011, Bradley 2012a). Also, due to the severity and spatial extent of liquefaction resulting from the 2010 Darfield earthquake,

a) Department of Civil and Environmental Engineering, Virginia Tech, 200 Patton Hall, Blacksburg, VA 24061

b) Department of Civil and Natural Resources Engineering, University of Canterbury, Private Bag 4800, Christchurch 8140, New Zealand

c) Department of Civil, Architectural, and Environmental, University of Texas at Austin, 301 E. Dean Keeton St., Austin, TX 78712-1056

d) Department of Civil and Environmental Engineering, University of Auckland, Private Bag 92019, Auckland 1142, New Zealand 
the New Zealand Earthquake Commission (EQC) funded an extensive subsurface characterization program for Christchurch, with over 10,000 CPT soundings performed to date.

The combination of well-documented liquefaction response during multiple events, densely recorded ground motions for the events, and detailed subsurface characterization provides an unprecedented opportunity to add numerous quality case histories to the liquefaction database. However, as discussed in Idriss and Boulanger (2012), the position of the cyclic resistance ratio (CRR) curve, which is central to simplified liquefaction evaluation procedures, is often controlled by relatively few case histories. Toward this end, the authors selected 25 sites to analyze in detail, many of which had minor surficial liquefaction manifestations resulting from the Darfield or Christchurch earthquake. The sites were evaluated during both these events, resulting in 50 high-quality case histories. The sites selected for detailed evaluation were located relatively close to strong ground motion stations and were characterized by both CPT soundings and surface wave testing.

The authors use the case histories to evaluate existing deterministic, CPT-based simplified liquefaction evaluation procedures, namely the procedures proposed by Robertson and Wride (1998; hereinafter, R\&W98), Moss et al. (2006; hereinafter, MEA06), and Idriss and Boulanger (2008; hereinafter, I\&B08). These procedures were assessed by comparing predicted and observed liquefaction responses at the sites, where the liquefaction responses were determined using one or more of these three methods: (1) post-earthquake site visits by the authors; (2) examination of high resolution aerial and satellite imagery; and/or (3) interviews with residents who lived near the case history sites. An error index is proposed to quantify the predictive capabilities of the three CPT-based procedures for the 50 selected case histories.

Background information on geology of the Canterbury Plains and on the Darfield and Christchurch earthquakes is presented first, with emphasis on information relevant to liquefaction. Next, the ground motions recorded during the Darfield and Christchurch earthquakes are discussed in relation to how the peak ground accelerations (PGA) at the case history sites were estimated, followed by a discussion of how the liquefaction case histories were interpreted with a subsequent detailed discussion of five of the 25 case history sites. The results from the case histories are then used to evaluate the R\&W98, MEA06, and I\&B08 procedures. An extensive Electronic Supplement is provided that details all the case histories and the authors' interpretations. This will allow subsequent researchers to perform their own interpretations, if they desire to do so.

\section{GEOLOGY AND GEOMORPHOLOGY OF THE CHRISTCHURCH AREA}

The Canterbury Plains are $\sim 160 \mathrm{~km}$ long and up to $60 \mathrm{~km}$ wide. The plains are the result of overlapping alluvial fans produced by glacier-fed rivers from the Southern Alps, the main mountain range of the South Island (Forsyth et al. 2008). Uplift of the Southern Alps resulted in rapid deposition during the late Quaternary and inundation of the Canterbury Plains by alluvial and fluvial sediments. The alluvial gravels underlying the Canterbury Plains typically have thicknesses of at least $500 \mathrm{~m}$. Most of the soils in the region are derived from greywacke from the Southern Alps or from loess (fine silt blown from riverbeds). In addition, some soils near Christchurch include clay and other minerals eroded from the extinct volcanic complex forming Banks Peninsula (Brown et al. 1995). 
Most of Christchurch was once low-lying floodplains and swamps behind a series of barrier dunes (composed of fine-grained beach/dune sand), estuaries, and lagoons (underlain by fine-grained deposits) of Pegasus Bay. The Waimakariri River regularly flooded Christchurch before levee construction and river realignment, shortly after the city was established in 1850 . The original city center was constructed on slightly higher ground compared to areas to the north and east. Of particular relevance to liquefaction susceptibility in Christchurch and its environs are the locations of abandoned paleo-channels of the Waimakariri, Heathcote, and Avon Rivers, and former swamps. These areas are underlain by, and filled with, young loose sandy sediments, with shallow groundwater levels (from $1 \mathrm{~m}$ to $5 \mathrm{~m}$ below ground surface), which are highly susceptible to liquefaction (e.g., Wotherspoon et al. 2012).

Samples of liquefaction ejecta were collected from several sites around Christchurch and Kaiapoi. The grain characteristics of these samples were analyzed using a scanning electron microscope (SEM), energy-dispersive X-ray spectrometry (EDS), X-ray diffraction (XRD), and a laser particle size analyzer. Although the characteristics of the collected samples varied, most can be described as silty fine sand having subrounded particle shapes. The EDS and $\mathrm{XRD}$ analyses showed that the ejecta is predominantly quartz and feldspar, which is consistent with the hypothesis that the material was derived from Torlesse Greywacke sandstone in the Southern Alps. The grain size distributions obtained from the laser particle size analyses indicate that the samples classify as SP, SM, and SP-SM, per ASTM D-2487 (ASTM, 2011).

\section{GROUND MOTIONS}

The 2010-2011 Canterbury earthquake sequence started at 4:35 am on 4 September 2010 NZ Standard Time (16:35 3 September 2010 UTC), when a previously unmapped fault west of Christchurch ruptured, producing the $M_{w} 7.1$ Darfield earthquake (Bradley et al. 2014). Although the earthquake caused major damage to the built environment and induced widespread liquefaction, there were no fatalities or major injuries. The Canterbury earthquake sequence included twelve other events having $M_{w} \geq 5.0$ with epicentral locations within $20 \mathrm{~km}$ of Christchurch (GeoNet, 2012), and up to ten of these larger events are known to have induced liquefaction (Quigley et al. 2013). However, the $M_{w} 6.2,22$ February 2011 Christchurch earthquake was the most damaging event, due to the close proximity of its rupture plane to Christchurch, resulting in 185 fatalities and causing widespread liquefaction (e.g., Cubrinovski et al. 2011, Cubrinovski et al. 2012, Green et al. 2011, Maurer et al. 2013, Orense et al. 2011, Robinson et al. 2013).

The motions from both the Darfield and Christchurch earthquakes were recorded by a dense network of strong ground motion stations (e.g., Cousins and McVerry 2010, Bradley and Cubrinovski 2011, Bradley 2012a and 2012b, Bradley et al. 2014). To evaluate the factor of safety against liquefaction per the simplified procedures used herein, the amplitude of cyclic loading is proportional to the PGA at the ground surface and the duration is related to the earthquake magnitude. Using the accelerograms recorded at the strong motion stations (GeoNet 2012), the conditional PGA distributions at the case history sites were computed using the procedure briefly outlined in Part A of the Electronic Supplement and discussed in detail by Bradley (2013a). This approach is similar to that used by Green et al. (2011) and 


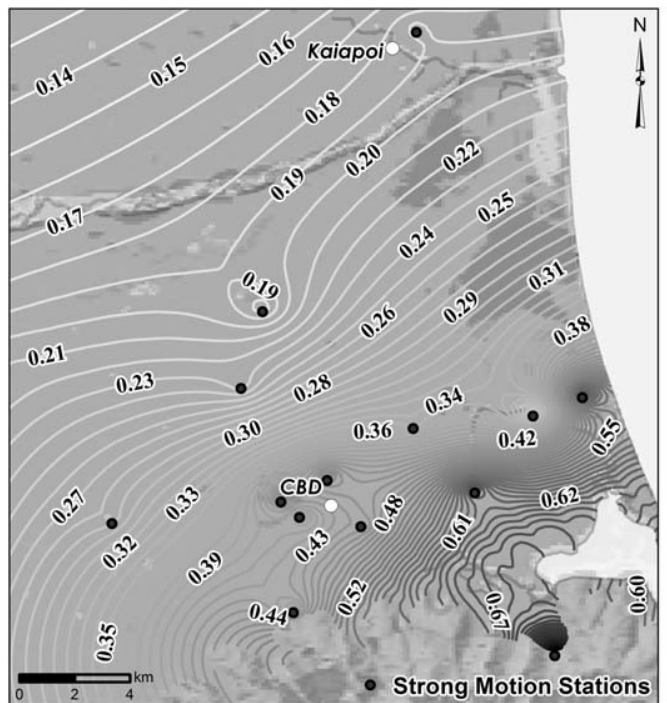

(a)

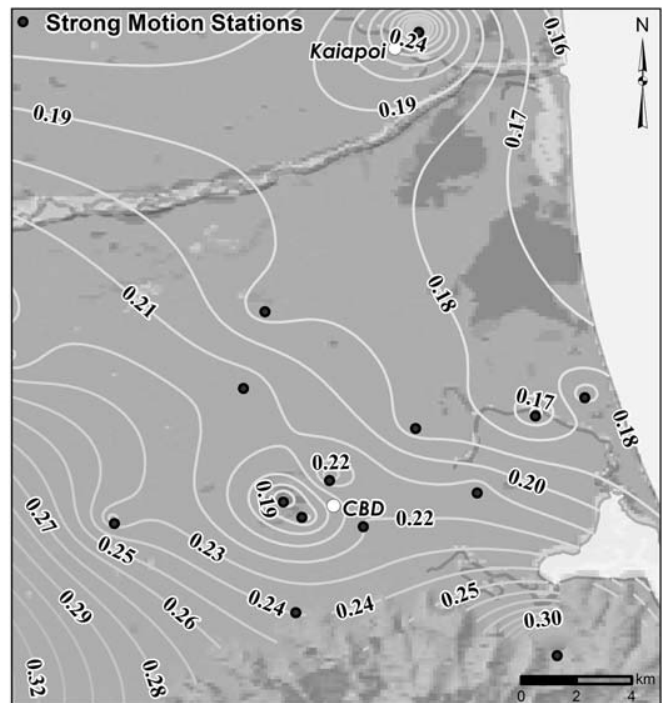

(b)

Figure 1. Contours of computed conditional PGAs (g): (a) Darfield earthquake and (b) Christchurch earthquake.

Maurer et al. (2014). Contour maps of the computed conditional PGAs for the Darfield and Christchurch earthquakes are shown in Figure 1.

\section{LIQUEFACTION CASE HISTORIES}

As mentioned above, and as shown in Figure 2, widespread liquefaction was induced during both the Darfield and Christchurch earthquakes. While there was certainly significant overlap in the areas that liquefied during these events, there were also areas that liquefied during the Darfield event that had no or only minor surficial liquefaction manifestations resulting from the Christchurch event, or vice versa. It was these areas that the authors targeted for further investigation because these sites would seemingly yield data that would best constrain the position of a CRR curve. Additionally, in order to minimize the uncertainty in the seismic loading at the sites, the authors further refined the targeted sites to those that were relatively close to strong motion stations.

Using the above criteria, approximately 60 sites were selected for potential detailed analyses. However, over half of these sites were removed from further consideration after reviewing their CPT logs and other in situ test data (e.g., the CPT sounding was terminated due to a shallow gravel layer or there was significant ambiguity in determining which layer liquefied). The authors revisited the remaining 25 sites to better determine their response during the Darfield and Christchurch earthquakes (note that the authors had previously visited many of these sites immediately following the Darfield and Christchurch earthquakes as part of post-earthquake reconnaissance efforts (Cubrinovski and Green 2010, Cubrinovski et al. 2011). During the revisits, interviews with local residents that were in the area at the time of the earthquakes were particularly helpful, with some having taken photos of the sites 


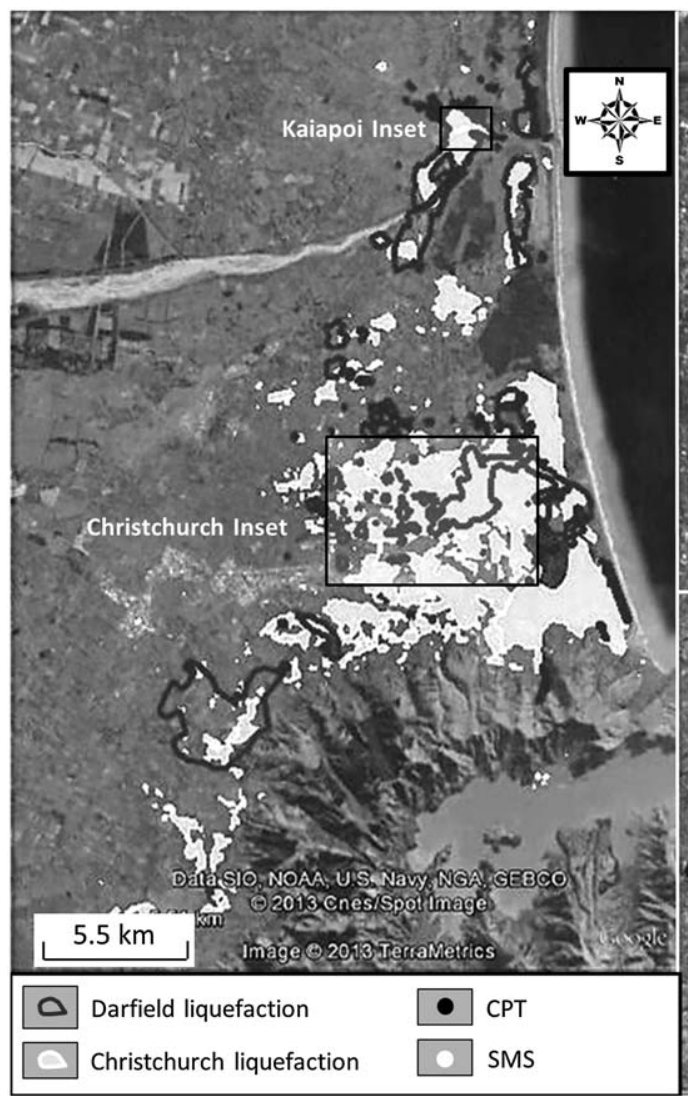

(a)

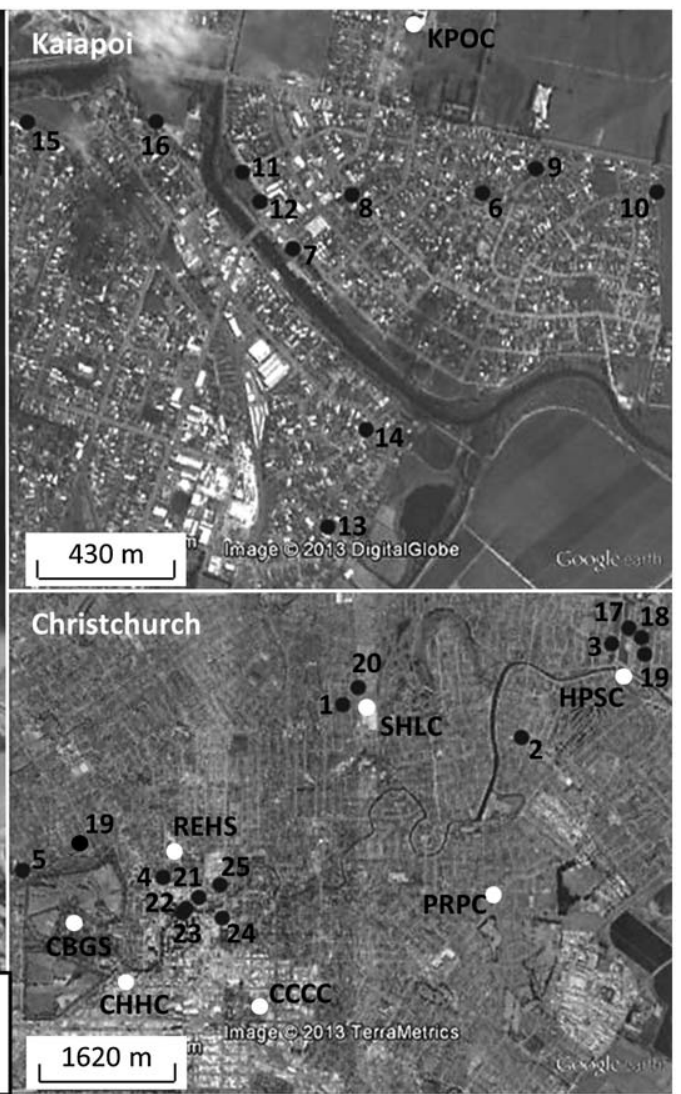

(b)

Figure 2. (a) Areas that liquefied during the $M_{w} 7.1$ Darfield earthquake (bound by dark lines) and areas that liquefied during the $\mathrm{M}_{\mathrm{w}} 6.2$ Christchurch earthquake (white shaded areas). (b) Locations of case history sites (numbered, dark dots) and strong motion seismograph stations (labeled, white dots).

immediately after the earthquakes. Finally, high resolution aerial photographs and satellite imagery taken within a few days after the earthquakes were used to further determine the liquefaction response at the selected sites.

\section{SHEAR WAVE PROFILING OF CASE HISTORY SITES}

The authors performed active-source surface wave testing (SASW and MASW) at each of the 25 sites to resolve the shear stiffness and layering of the soil profile. The surface wave testing employed a linear receiver array composed of $244.5 \mathrm{~Hz}$ geophones with an equal spacing $(\Delta x)$ of either $0.9 \mathrm{~m}$ or $1.5 \mathrm{~m}$. For MASW testing, the multiple source offset method was used with three separate source-to-first-receiver distances of $4.6 \mathrm{~m}, 9.1 \mathrm{~m}$, and $18.3 \mathrm{~m}$ (Cox and Wood, 2011). The SASW data was analyzed using the phase unwrapping method to determine the individual dispersion curves from each receiver spacing. The MASW data 
was analyzed using the frequency domain beamformer method (Zywicki 1999). Once the surface wave dispersion trends from each method were obtained, a composite dispersion curve was generated by combining the dispersion data from SASW and MASW. The mean and standard deviation of the dispersion data was calculated based on Rayleigh wave phase velocity $\left(V_{R}\right)$ and wavelength according to Cox and Wood (2011). The shear wave velocity profile was then determined by fitting a 3D theoretical solution (i.e., effective mode inversion) to the mean experimental dispersion curve using the software WinSASW. The water tables used in the forward modeling were determined using either piezo-CPT sounding data (i.e., CPTu data) and/or P-wave refraction results. The shear wave velocity profiles obtained from forward modeling of each site were limited to the maximum experimental wavelength divided by two (i.e., $\lambda_{\max } / 2$ ). For additional information regarding the surface wave testing conducted as part of this study refer to Wood et al. (2011).

As discussed below, the shear wave velocity profiles were used to help interpret the soil profile at each site and to compute the average shear wave velocity over the top $12 \mathrm{~m}\left(V_{S 12}\right)$, which was used in conjunction with the MEA06 simplified liquefaction evaluation procedure. The shear wave velocity profiles were also used to evaluate liquefaction susceptibility using various simplified $V_{S}$ liquefaction triggering relationships. However, these evaluations are still ongoing and are not presented in this paper.

\section{SELECTION OF CRITICAL LAYERS}

The "critical" layers for each of the 25 case history sites were selected using the in situ test data (i.e., CPT and $V_{S}$ profiles) and the liquefaction response information that the authors collected for each site. In the context of this study, the "critical" layer is the soil layer that is believed to have liquefied and caused the observed surface manifestations for cases where surficial liquefaction manifestations were observed. For cases where no evidence of liquefaction was observed, the "critical" layer is that which is believed to be the most susceptible to liquefaction and that would have resulted in at least minor surficial manifestations if it indeed liquefied during an earthquake. The guiding principle in selecting the critical layers was that the depth-thickness-density combination of the critical layer for a given site be consistent with the observed liquefaction response of the site. The general rules developed by Green et al. (2005) and Olson et al. (2005) for interpreting paleoliquefaction sites in the Central United States were used. These rules are:

1. Severe surficial liquefaction manifestation (e.g., extensive ground cracking and massive sand boils on the ground surface) requires a relatively thick, loose liquefiable stratum. The deeper the stratum, the thicker it needs to be for these features to manifest at the ground surface.

2. Moderate surficial liquefaction manifestation (e.g., moderate sized ground cracking and moderate sized sand boils on the ground surface) can result from a slightly thinner, slightly denser, and/or slightly deeper liquefiable stratum as compared to (1).

3. Minor surficial liquefaction manifestations (e.g., limited ground cracking, limited surface ejecta, and/or limited seeping of water on the ground surface) can result from a relatively loose, thin, deep layer severely liquefying, from a relatively loose to medium dense, thick, shallow layer having highly elevated excess pore 
pressures but not necessarily liquefying, or from a relatively dense, thick, shallow layer marginally liquefying. The thickness of the loose stratum would have to increase the deeper the stratum is below the surface, while the density of the medium-dense stratum would have to decrease the deeper the stratum is.

4. The critical layer associated with lateral spreading can be relatively thin, with its thickness and density increasing and decreasing, respectively, the larger the amount of the surface ejecta and the wider the lateral spread cracks, respectively. However, the critical layer should be selected by also considering the slope of the ground surface, the height of the free face, and the lateral continuity of the liquefiable stratum relative to the lateral spread area.

As described above, the liquefaction responses for the case histories are categorized as "No Liquefaction," "Minor Liquefaction," "Moderate Liquefaction," "Severe Liquefaction," and "Lateral Spreading." As the naming scheme implies, "No Liquefaction" includes all the cases where no liquefaction surface manifestations were observed, "Minor Liquefaction" includes all the cases where minor surficial liquefaction manifestations were observed, "Moderate Liquefaction" and "Severe Liquefaction" include all cases where the observed liquefaction surface manifestations were more severe than "Minor Liquefaction," and "Lateral Spreading" includes cases where liquefaction was manifested at the ground surface in the form of lateral spreading cracks, etc. Table ESB-1 in Part B of the Electronic Supplement provides quantitative metrics for the severity categorization used herein. However, because the severity of surficial liquefaction manifestations is a continuum ranging from none to very severe, any sort of discrete categorization of "Minor," "Moderate," and "Severe" is inherently subjective, regardless of the best efforts to quantify liquefaction severity. To help reduce ambiguity in how the authors classified the case histories presented herein, Part B of the Electronic Supplement also gives examples of high resolution aerial images of the different severity manifestation categories.

Implementing the above rules to select the critical layers at each case history site requires considerable judgment, and several of the $\sim 60$ sites that were initially selected for detailed analysis were removed from further consideration because of the significant ambiguity in constraining the depth/thickness of the critical layers. Additionally, in several of the remaining sites, both preferred and alternative critical layers were selected. Finally, it is debatable whether or not lateral spreading case histories should be included in the liquefaction triggering database. These case histories are often more difficult to interpret than level ground liquefaction cases, and require extensive in situ test data to properly interpret (more extensive than is often performed). Accordingly, it is the opinion of the authors that if lateral spread case histories are included in the liquefaction triggering database, they should generally be given less weight when using them to develop or to evaluate CRR curves. Of the 25 sites included in this study, only two were lateral spread cases, one of which is presented in detail below, and both are briefly discussed in relation to the observed surface manifestations versus their predicted response by R\&W98, MEA06, and I\&B08.

Before applying the above general rules for selecting the critical layers, the soil type and soil density needed to be estimated from the available in situ test data. Toward this end, CPT logs were used to compute the soil behavior type index, $I_{c}$, for each site as a function of depth. Table 1 lists values of $I_{c}$ and the corresponding inferred soil type (Robertson and 
Table 1. Boundaries of soil behavior type (Robertson and Wride 1998)

\begin{tabular}{ll}
\hline \hline Soil Behavior Type Index, $I_{c}$ & \multicolumn{1}{c}{ Inferred Soil Type } \\
\hline$I_{c}<1.31$ & Gravelly sand to dense sand \\
$1.31<I_{c}<2.05$ & Sands: clean sand to silty sand \\
$2.05<I_{c}<2.60$ & Sand mixtures: silty sand to sandy silt \\
$2.60<I_{c}<2.95$ & Silt mixtures: clayey silt to silty clay \\
$2.95<I_{c}<3.60$ & Clays: silty clay to clay \\
$I_{c}<3.60 I_{c}$ & Organic soils: peats \\
\hline \hline
\end{tabular}

Wride, 1998). Following Youd et al. (2001), in the absence of site specific sampling and testing, soils having an $I_{c}>2.4$ were considered to be non-liquefiable. The relative densities $\left(D_{r}\right)$ were then estimated for soils having $I_{c}<2.4$ using the relationship derived from Robertson and Cabal (2012):

$$
D_{r}(\%)=\frac{1}{c} \cdot \frac{q_{c} / p_{a}}{\left(\frac{\sigma_{v}^{\prime}}{p_{a}}\right)^{0.5}}
$$

where $q_{c}=$ measured cone tip resistance; $\sigma^{\prime}{ }_{v}=$ vertical effective stress; $P_{a}=$ atmospheric pressure in the same units as $q_{c}$ and $\sigma^{\prime}{ }_{v}$; and

$$
\begin{aligned}
c & =300-\left(1.32-I_{c}\right) \cdot \frac{300-400}{1.32-2.07} \text { for } 1.32 \leq I_{c} \leq 2.07 \\
& =300 \text { for } I_{c}<1.32 \\
& =400 \text { for } I_{c}>2.07
\end{aligned}
$$

Once the $I_{c}$ and $D_{r}$ profiles were computed for all the sites, the critical layers for each site were selected using the general rules listed above, with the estimated $D_{r}$ values used in a relative sense for a given profile as opposed to being used in an absolute sense. That is for a given profile, the computed $D_{r}$ values are used to determine density of one stratum relative to another as opposed to determining the relative density of the strata in absolute terms.

As may be noted, the above rules for selecting critical layers do not explicitly take into account the variation of the induced cyclic stress as a function of depth, although this is somewhat taken into account through judgment in selecting the critical layer. However, to assess the influence of the depth dependency of the induced seismic demand, the factor of safety against liquefaction $\left(\mathrm{FS}_{\mathrm{liq}}\right)$ was computed using the various simplified liquefaction evaluation procedures to determine if there were any credible alternative critical layers for the profiles. If there were, judgment was be used in revising the selected critical layers. However, this is a secondary step, and the authors view it as being different from using a given simplified liquefaction evaluation procedure to select the critical layers and then turning around and using these case histories to validate the predictive capabilities of the same simplified liquefaction evaluation procedure (or to invalidate the predictive capabilities of different simplified liquefaction evaluation procedures). 


\section{SUMMARY OF CASE HISTORIES}

The locations of the 25 high-quality sites selected for detailed analyses are shown in Figure 2. The sites are primarily located in three general areas: (1) Christchurch's Central Business District (CBD), (2) northeastern suburbs of Christchurch, and (3) north and south Kaiapoi. Again, these sites were selected because they are relatively close to strong motion seismographs (within $\sim 1.65 \mathrm{~km}$ ) and because they liquefied during the Darfield event and had either no or only minor surficial liquefaction manifestations resulting from the Christchurch event, or vice versa. The names used to designate the sites in Table ESC-1 in Part C of the Electronic Supplement are those of the representative CPT sounding performed at the sites.

Representative values of $q_{c}$ and sleeve friction $\left(f_{s}\right)$ for the critical layers for each of the case histories are presented in Table ESC-1. However, as discussed in Robertson (2009), using single "representative" values of $q_{c}$ and $f_{s}$ to evaluate liquefaction potential of the entire critical layer can sometimes yield misleading results. This is because single values of the CPT indices do not necessarily reflect the variation of the soil properties within a critical layer. This was handled by the authors, to the extent possible, by selecting critical layers that are fairly uniform in their properties (e.g., see discussion on site FND-01 below). Additionally, the normalizing factors applied to the measured $q_{c}$ values vary nonlinearly with effective confining stress and fines content (FC). As a result, using average values of $q_{c}$ and $f_{s}$ to develop a representative normalized tip resistance for a given layer (i.e., normalizing for the effects of effective overburden pressure and FC) can yield a different representative normalized tip resistance than one developed by first normalizing all the measured $q_{c}$ values in the layer and then computing the average of these normalized values. From a mathematical perspective, the latter approach is more correct than the former, and thus was used herein to compute the normalized tip resistances for the critical layers per the three liquefaction evaluation procedures evaluated.

Due to space limitations, only 5 of the 25 sites are presented in detail below. These five sites ranged in difficulty of interpretation, and thus fully illustrate the implementation of the general rules presented above for selecting critical layers. However, because the interpretation of liquefaction case histories is inherently subjective, Part C of the Electronic Supplement details each of the case histories, which both illustrates the authors' interpretations and will allow subsequent researchers to perform their own interpretation, if they desire to do so.

\section{Site 1: CPT-SHY-09}

Site 1: CPT-SHY-09 is located on Hercules Street, just east of the intersection of Hercules and Hope Streets in the northeastern suburb of Richmond. The site is approximately $0.27 \mathrm{~km}$ from the SHLC strong motion seismograph station, and the estimated geometric means of the horizontal PGAs at the site during the Darfield and Christchurch earthquakes are $0.187 \mathrm{~g}$ and $0.347 \mathrm{~g}$, respectively. There were no observed surface manifestations of liquefaction following the Darfield earthquake, but there was evidence of "Moderate Liquefaction" at the site following the Christchurch earthquake.

The measured CPT $q_{c}$, friction ratio $\left(R_{f}=f_{s} / q_{c}\right), I_{c}$, and $D_{r}$ as functions of depth for SHY-09 are plotted in Figure 3. Superimposed on these plots is the selected critical layer for both the Darfield and Christchurch earthquakes. The critical layer is relatively shallow and is 

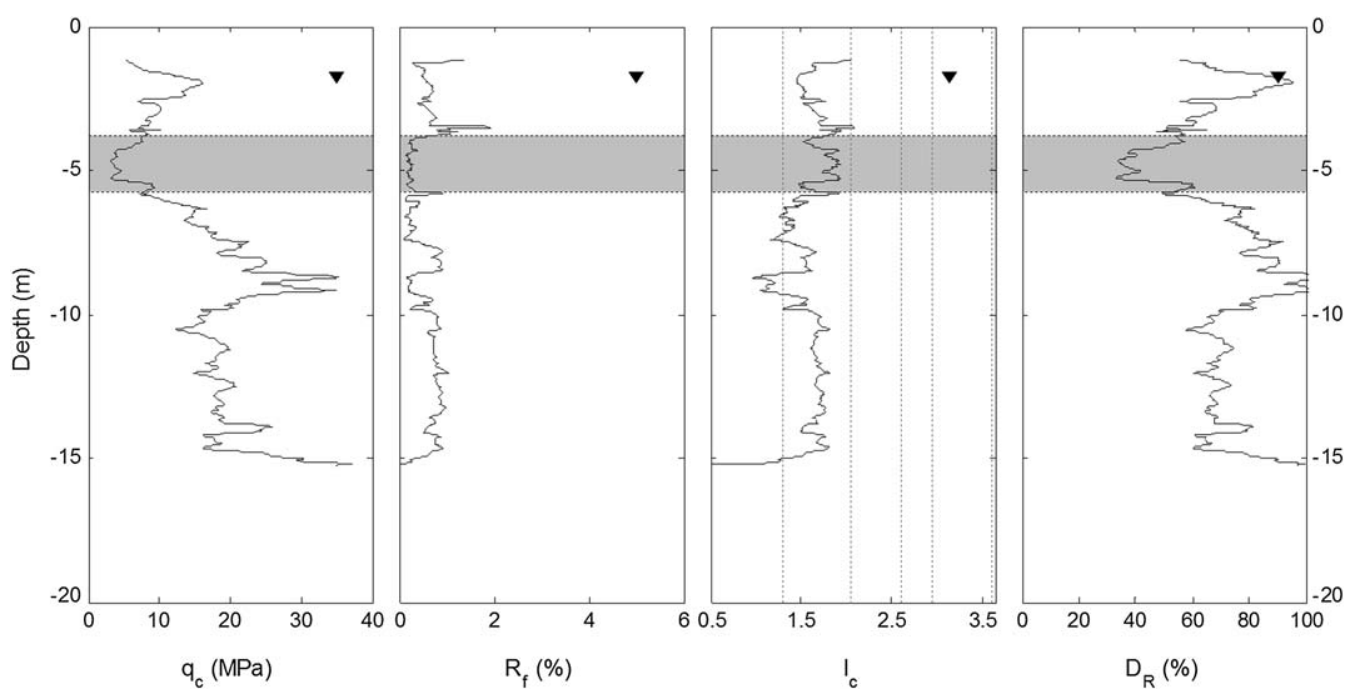

Figure 3. Measured CPT tip resistance $\left(q_{c}\right)$, friction ratio $\left(R_{f}\right)$, soil behavior type index $\left(I_{c}\right)$, and estimated relative densities $\left(D_{r}\right)$ as functions of depth for Site 1: CPT-SHY-09. Superimposed on these plots is the selected critical layer for both the Darfield and Christchurch earthquakes.

approximately $2 \mathrm{~m}$ thick. Using the $I_{c}$-soil type correlation presented in Table 1 and Equation 1, the inferred soil type for the layer is loose "clean sand to silty sand." Following the general rules outlined above for selecting critical layers, the authors selected the layer shown in Figure 3 because its depth-thickness-density combination is believed to be consistent with the surficial liquefaction manifestations observed during the both the Darfield and Christchurch earthquakes. That is, in the authors' judgment, the depth-thickness-density combination of the critical layer is such that surface manifestations would have resulted if this layer liquefied during the Darfield earthquake; similarly, if this layer liquefied during the Christchurch earthquake, its depth-thickness-density combination is sufficient to have caused moderate surface liquefaction manifestations observed at the site.

\section{Site 4: CPT-CBD-21}

Site 4: CPT-CBD-21 is located near the northwest corner of the intersection of Durham and Salisbury Streets in Christchurch's CBD. The site is approximately $0.3 \mathrm{~km}$ from the REHS strong motion seismograph station, and the estimated geometric means of the horizontal PGAs at the site during the Darfield and Christchurch earthquakes are $0.219 \mathrm{~g}$ and $0.460 \mathrm{~g}$, respectively. There were no observed surface manifestations of liquefaction following the Darfield earthquake, but there were minor surficial liquefaction manifestations following the Christchurch earthquake. Because of the limited consequences of "minor" liquefaction to the built and natural environment, other investigators in previous studies sometimes have classified sites that had minor surficial liquefaction manifestations as "no liquefaction." However, due to the potential for minor liquefaction case histories to help constrain the position of the CRR curve, the authors prefer to categorize these sites separately with the designation of "Minor Liquefaction." This is because excess pore 
water pressures were certainly elevated at these sites as a result of the earthquake shaking, but the thickness-depth-severity combination of the critical layer was such that the surface manifestations were minor. To illustrate Minor Liquefaction as defined in this study, a high resolution aerial photograph of CBD-21 taken two days after the Christchurch earthquake is shown in Figure 4. At this site, a small amount of liquefaction ejecta surfaced along the edge of road (a few cm thick at most). There was no visible distress to the adjacent structure, to the pavement, or buried utilities (if present) due to liquefaction at this site (i.e., after the limited amount of ejecta was cleaned up, there was no evidence of liquefaction at the site; note that authors returned to this site periodically from the time of the earthquakes to the time of the writing of this paper).

The measured CPT tip resistance $\left(q_{c}\right)$, friction ratio $\left(R_{f}\right)$, soil behavior type index $\left(I_{c}\right)$, and estimated relative densities $\left(D_{r}\right)$ as functions of depth for CBD-21 are plotted in Figure 5 . Superimposed on these plots is the selected critical layer for both the Darfield and Christchurch earthquakes. The critical layer is $\sim 4.5 \mathrm{~m}$ deep and is approximately $2 \mathrm{~m}$ thick. Using the $I_{c}$-soil type correlation presented in Table 1 and Equation 1, the inferred soil type for the layer is dense "clean sand to silty sand." Per the general rules outlined above for selecting critical layers, the authors selected the layer shown in Figure 5 because its depth-thickness-density combination is believed to be consistent with the liquefaction surface manifestation (or lack thereof) observed during the both the Darfield and Christchurch earthquakes.

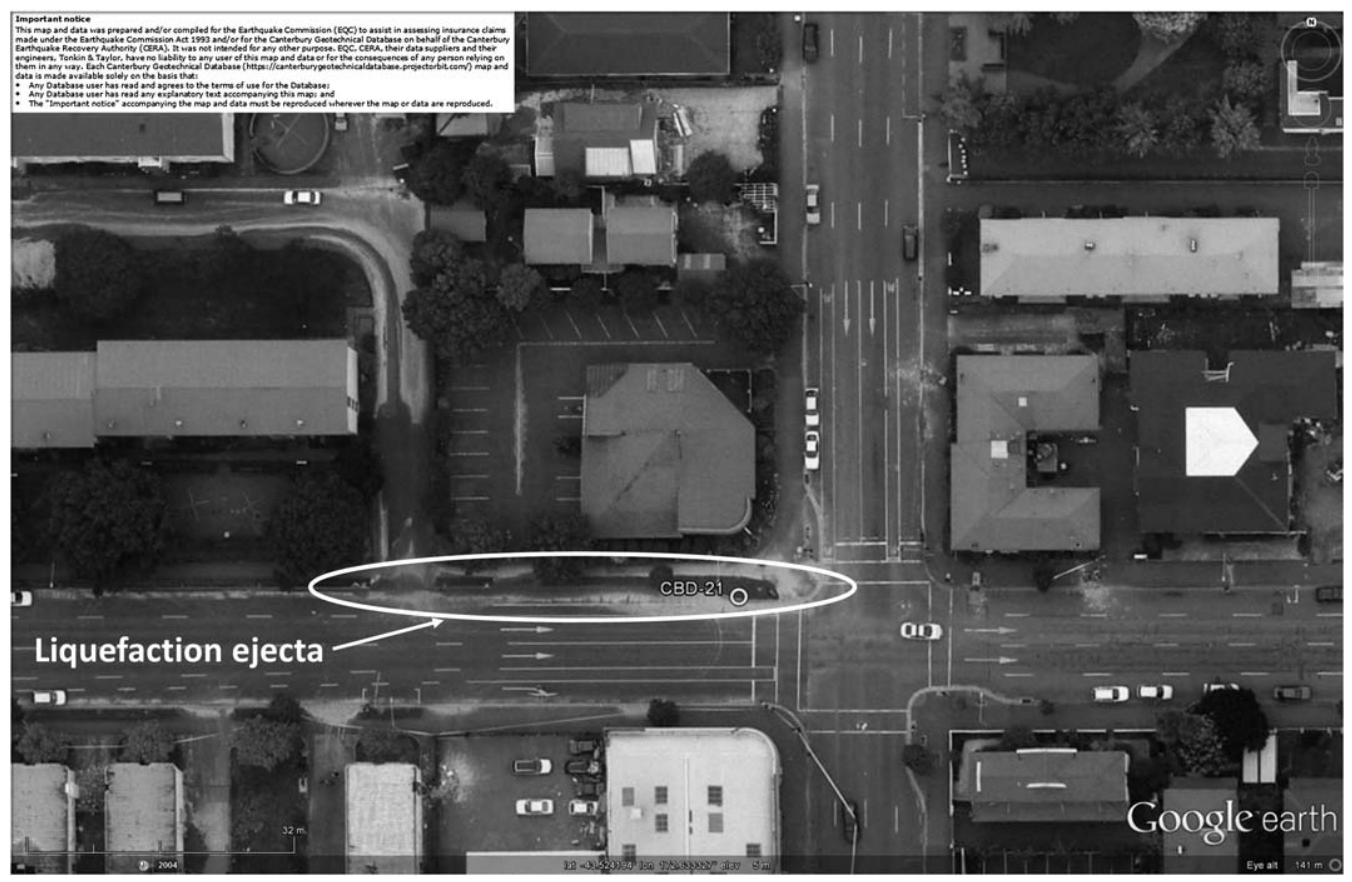

Figure 4. High resolution aerial photograph of Site 4: CPT-CBD-21 taken two days after the Christchurch earthquake illustrating "minor" liquefaction as defined in this study. 

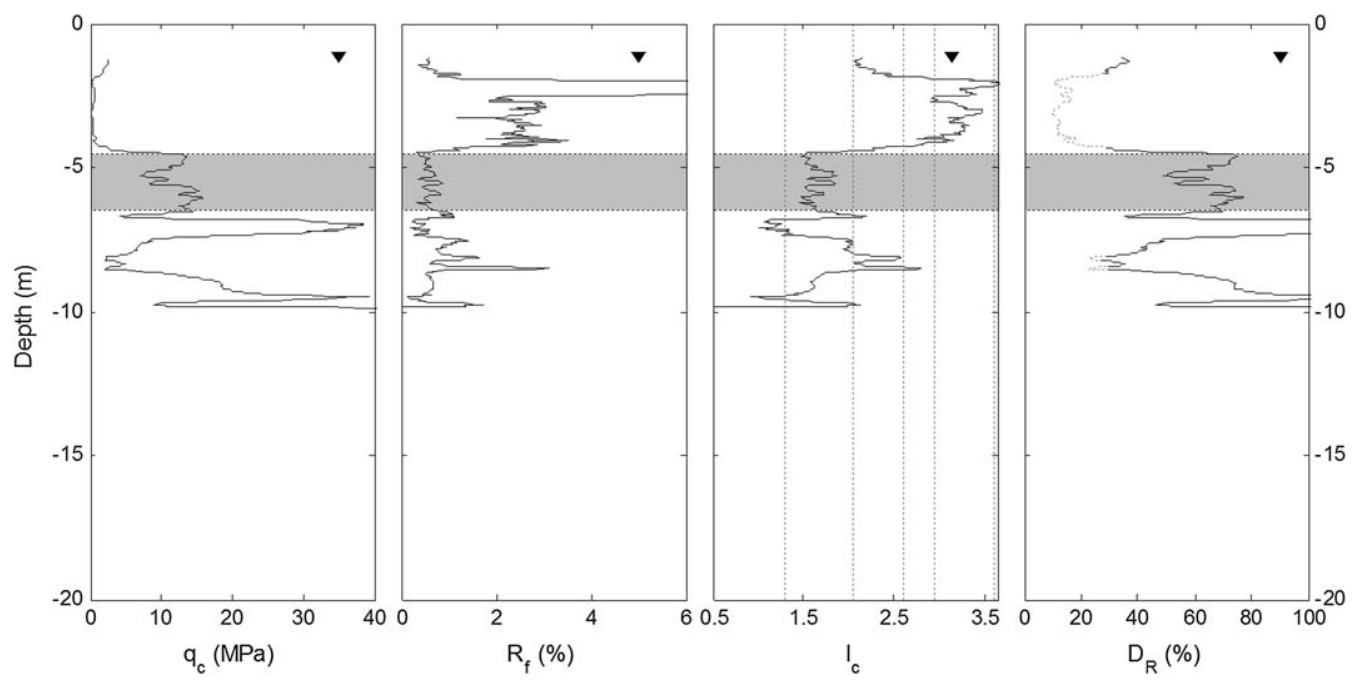

Figure 5. Measured CPT tip resistance $\left(q_{c}\right)$, friction ratio $\left(R_{f}\right)$, soil behavior type index $\left(I_{c}\right)$, and estimated relative densities $\left(D_{r}\right)$ as functions of depth for Site 4: CPT-CBD-21. Superimposed on these plots is the selected critical layer for both the Darfield and Christchurch earthquakes.

\section{Site 5: CPT-FND-01}

Site 5: CPT-FND-01 is located northwest of the intersection of Fendalton Rd, Deans Ave, and Harper Ave in the suburb of Fendalton and is the western most site analyzed in this study. The site is approximately $0.9 \mathrm{~km}$ from the CBGS strong motion seismograph station, and the estimated geometric means of the horizontal PGAs at the site during the Darfield and Christchurch earthquakes are $0.199 \mathrm{~g}$ and $0.382 \mathrm{~g}$, respectively. The site experienced "Lateral Spreading" during the Darfield earthquake and "Severe Lateral Spreading" during the Christchurch earthquake.

The measured CPT tip resistance $\left(q_{c}\right)$, friction ratio $\left(R_{f}\right)$, soil behavior type index $\left(I_{c}\right)$, and estimated relative densities $\left(D_{r}\right)$ as functions of depth for CBD-21 are plotted in Figure 6. As inferred from these plots, the entire profile consists of relatively thin, alternating layers of coarse- and fine-grained soils, where the former are assumed to be liquefiable and the latter are assumed not to be. The observed surface manifestations of liquefaction likely resulted from several of the thin, coarse-grained layers liquefying, rather than just from a single layer liquefying. However, in lieu of averaging the properties of multiple layers having various inferred soil types, the authors opted to select one of the thin coarse-grained layers as being representative of all the thin, coarse-grained layers that likely liquefied during both the Darfield and Christchurch earthquakes. This layer is superimposed on the plots in Figure 6. Because the selected representative critical layer is relatively thin $(\sim 0.3 \mathrm{~m}$ thick), thin layer corrections were used in computing the normalized CPT tip resistances in accordance with the respective procedures outlined in R\&W98, MEA06, and I\&B08. 

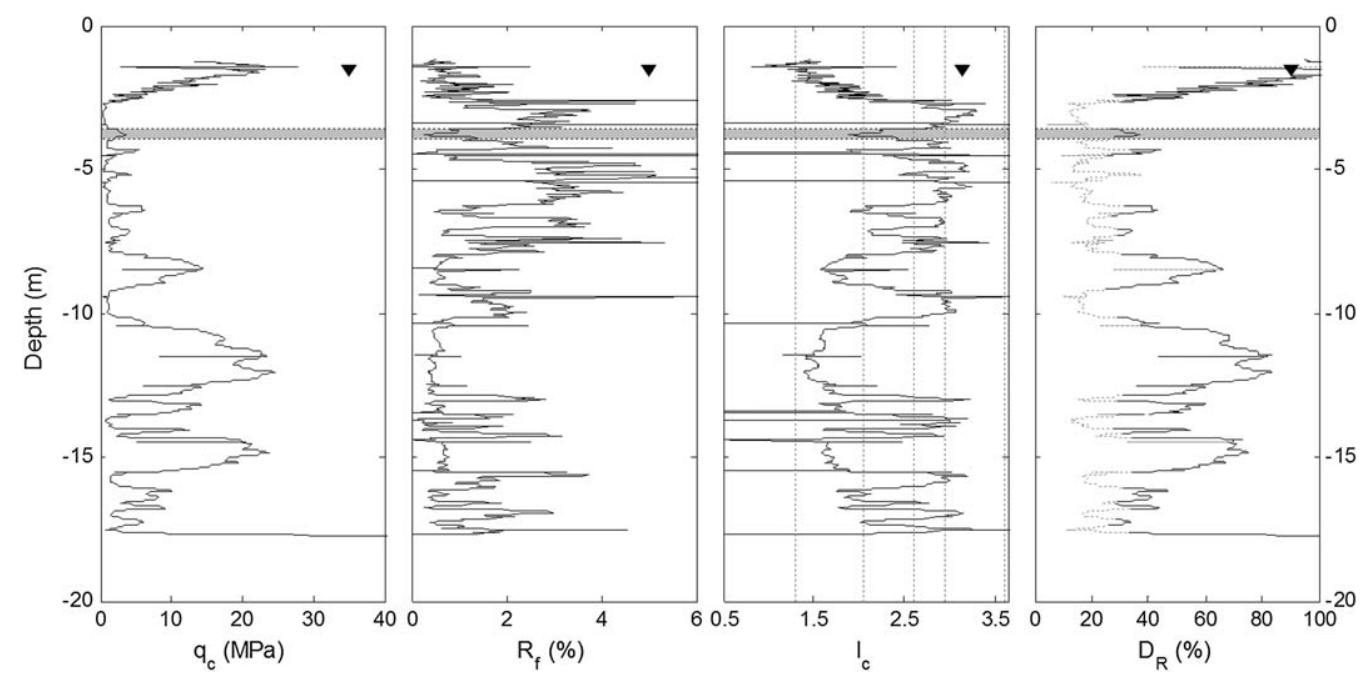

Figure 6. Measured CPT tip resistance $\left(q_{c}\right)$, friction ratio $\left(R_{f}\right)$, soil behavior type index $\left(I_{c}\right)$, and estimated relative densities $\left(D_{r}\right)$ as functions of depth for Site 5: CPT-FND-01. Superimposed on these plots is the selected representative critical layer for both the Darfield and Christchurch earthquakes.

\section{Site 11: CPT-KAN-26}

Site 11: CPT-KAN-26 is located in a park along the Kaiapoi River near the intersection of Charles and Davies Streets in North Kaiapoi. The site is approximately $0.75 \mathrm{~km}$ from the KPOC strong motion seismograph station, and the estimated geometric means of the horizontal PGAs at the site during the Darfield and Christchurch earthquakes are $0.231 \mathrm{~g}$ and $0.181 \mathrm{~g}$, respectively. Moderate surficial liquefaction manifestations formed during the Darfield earthquake and minor surficial liquefaction manifestations formed during the Christchurch earthquake. Although located near the Kaiapoi River, there was no evidence of lateral spreading at this site, but severe lateral spreading occurred along other stretches of the river banks, including the river bank opposite to this site.

The measured CPT $q_{c}, R_{f}, I_{c}$, and $D_{r}$ as functions of depth for KAN-26 are plotted in Figure 7. Superimposed on these plots are the selected critical layers for both the Darfield and Christchurch earthquakes. As shown, different critical layers were selected for the two earthquakes. The reason for this is consistency between the depth-thickness-density combinations of the critical layers and the liquefaction surface manifestations observed for the respective earthquakes. For example, the relatively loose and thin upper critical layer has a depth-thickness-density combination that could result in minor surface manifestations if it liquefied. However, because it is relatively thin, it is very doubtful that this layer could result in surface manifestations more severe than minor, in the absence of lateral spreading. Rather, more severe manifestations would require the thicker, deeper critical layer identified in Figure 7 to liquefy. This two-critical-layer hypothesis is supported by field observations. The ejecta associated with minor surface manifestations resulting from the Christchurch earthquake were brown in color, which is evidence of oxidation and the 

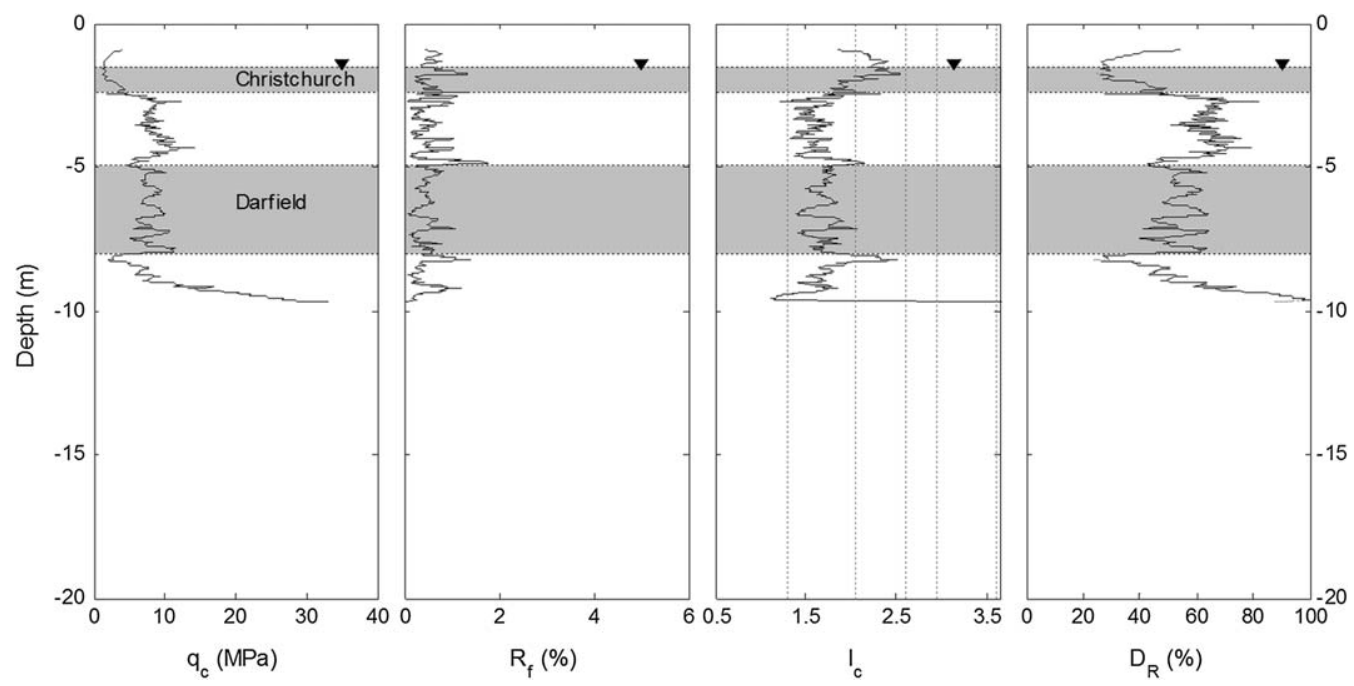

Figure 7. Measured CPT tip resistance $\left(q_{c}\right)$, friction ratio $\left(R_{f}\right)$, soil behavior type index $\left(I_{c}\right)$, and estimated relative densities $\left(D_{r}\right)$ as functions of depth for Site 11: CPT-KAN-26. Superimposed on these plots are the selected critical layers for the Darfield and Christchurch earthquakes.

development of iron oxide byproducts that result from exposure to oxygen through a fluctuating groundwater table near the ground surface or from being a fill material (i.e., a shallow layer). On the contrary, the moderate liquefaction surface manifestations that formed during the Darfield earthquake included both brown and blue-gray sand ejecta, which for the latter ejecta indicate the sand was in a reducing atmosphere, sealed from oxygen under the groundwater table, which is only possible for a deeper deposit (i.e., a deeper layer).

\section{Site 19: CPT-NBT-03}

Site 19: CPT-NBT-03 is located on Waygreen Ave, just south of the intersection of Waygreen Ave and Atlantis St, in the eastern Christchurch suburb of New Brighton. The site is approximately $0.4 \mathrm{~km}$ from the HPSC strong motion seismograph station, and the estimated geometric means of the horizontal PGAs at the site during the Darfield and Christchurch earthquakes are $0.168 \mathrm{~g}$ and $0.346 \mathrm{~g}$, respectively. The authors were told by local residents that only minor surficial manifestation resulted from the Darfield earthquake but that the site severely liquefied during the Christchurch earthquake (the severe surficial liquefaction manifestations resulting from the Christchurch earthquake were readily identifiable in the post-earthquake high resolution aerial imagery; however, the minor surficial liquefaction manifestations resulting from the Darfield earthquake were not readily identifiable in the aerial imagery).

The measured CPT $q_{c}, R_{f}, I_{c}$, and $D_{r}$ as functions of depth for NBT-03 are plotted in Figure 8. Superimposed on these plots is the selected critical layer for both the Darfield and Christchurch earthquakes. The critical layer is $\sim 7 \mathrm{~m}$ deep and is approximately $3.2 \mathrm{~m}$ thick. Using the $I_{c}$-soil type correlation presented in Table 1 and Equation 1, the inferred soil type 

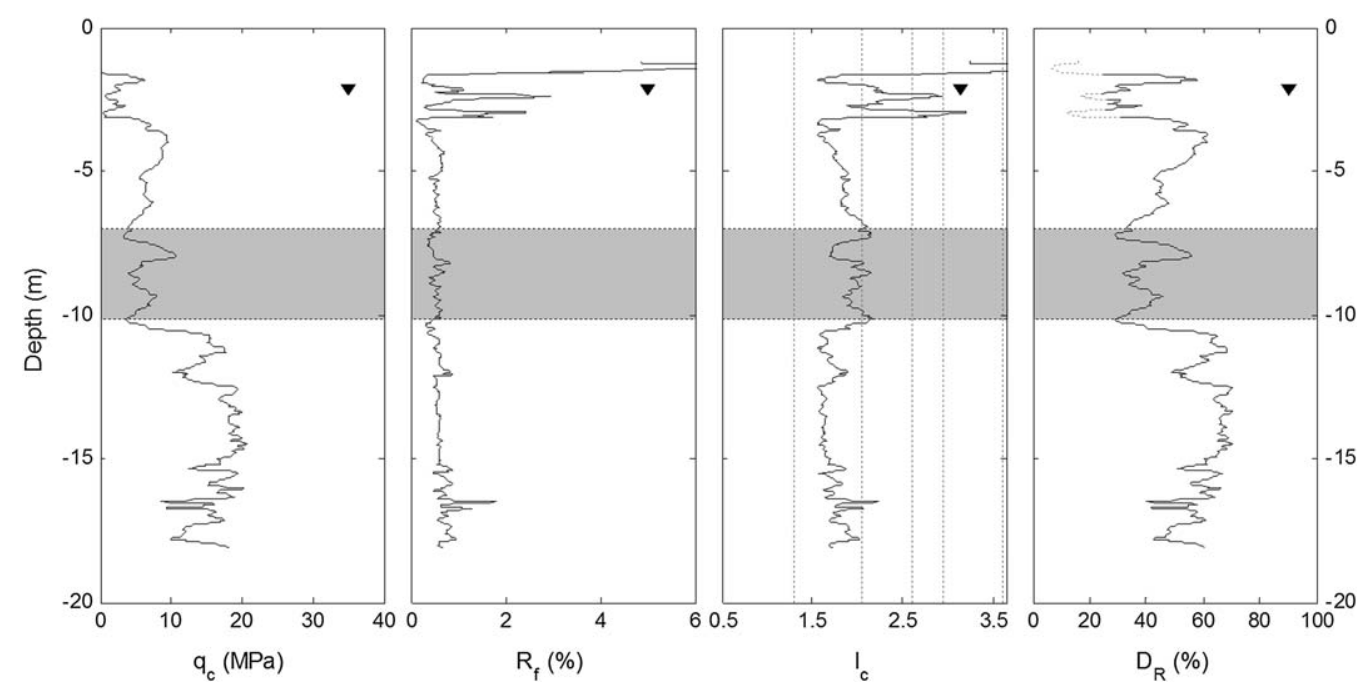

Figure 8. Measured CPT tip resistance $\left(q_{c}\right)$, friction ratio $\left(R_{f}\right)$, soil behavior type index $\left(I_{c}\right)$, and estimated relative densities $\left(D_{r}\right)$ as functions of depth for Site 19: CPT-NBT-03. Superimposed on these plots is the selected critical layer for both the Darfield and Christchurch earthquakes.

for the layer is "clean sand to silty sand" with thin strata of medium-dense "silty sand to sandy silt." Although the properties of the selected critical layer (e.g., inferred relative density and soil type) vary as a function of depth, the authors believe that the depth-thickness-density combination of the selected layer is consistent with the liquefaction surface manifestation observed during both earthquakes.

\section{EVALUATION OF EXISTING LIQUEFACTION EVALUATION PROCEDURES}

The 50 case histories analyzed in this study (i.e., 25 sites analyzed for two earthquakes) were used to evaluate the R\&W98, MEA06, and I\&B08 CPT-based, deterministic simplified liquefaction evaluation procedures. In Figure 9, the case history data are plotted together with the "clean sand" CRR curves for a magnitude 7.5 earthquake (i.e., $\mathrm{CRR}_{\mathrm{M} 7.5}$ ) and for $1 \mathrm{~atm}$ initial vertical effective confining stress $\left(\sigma_{\mathrm{v} 0}^{\prime}\right)$ for the three liquefaction evaluation procedures. For the MEA06 procedure, the "nonlinear shear mass participation factor" $\left(r_{d}\right)$ can be computed two ways, depending on whether $V_{S 12}$ for the site is known. Since $V_{S}$ profiles were measured at each site, the authors computed the $\operatorname{CSR}_{\mathrm{M} 7.5}$ (i.e., cyclic stress ratios normalized to a magnitude 7.5 earthquake) for the sites using both the $V_{S 12^{-}}$ independent and -dependent $r_{d}$ equations, where the former equation is given in Moss et al. (2006) and the latter in Cetin (2000). Both sets of CSR $\mathrm{M}_{\mathrm{M} .5}$ data are shown in Figure 9b, where the triangular and circular symbols correspond to the values computed using the $V_{S 12^{-}}$ dependent $r_{d}$ equations and the "end of the tails" extending from the triangular and circular symbols correspond to the values computed using the $V_{S 12}$-independent $r_{d}$ equations.

$\mathrm{FC}$ is required to compute normalized tip resistance per I\&B08, while normalized tip resistances per the R\&W98 and MEA06 are based on $I_{c}$ and $R_{f}$, respectively. The FC of 


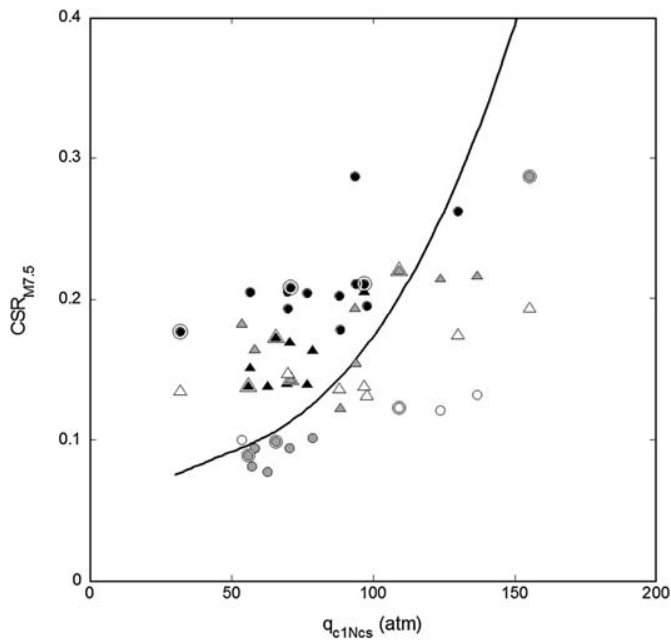

(a)

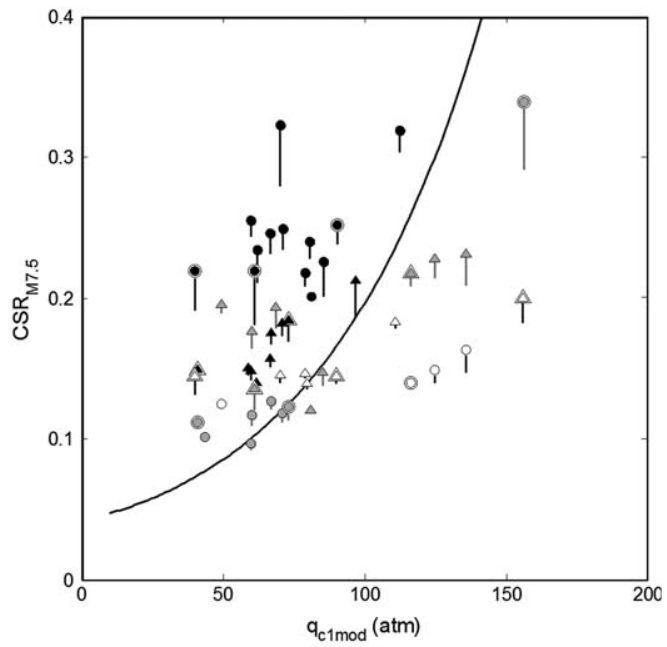

(b)

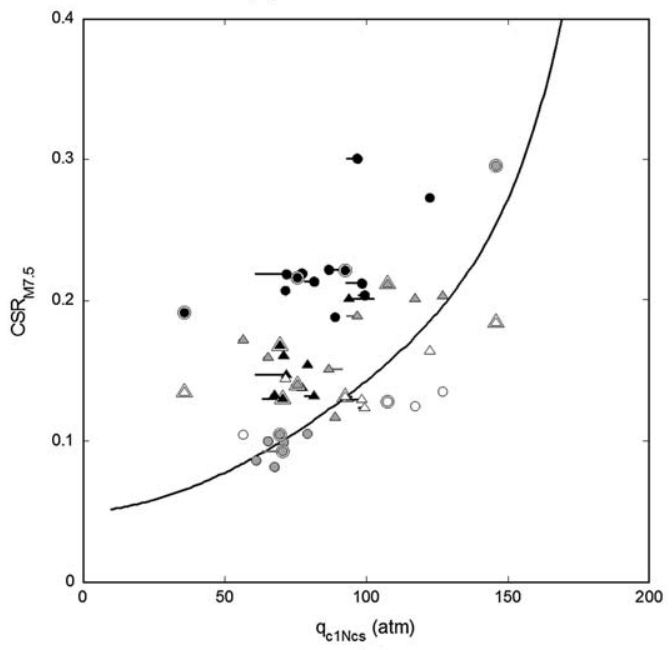

(c)

Figure 9. Case history data plotted together with $\mathrm{CRR}_{\mathrm{M} 7.5}$ curves: (a) R\&W98; (b) MEA06; (c) I\&B08. Note similar plots are contained in Part D of the Electronic Supplement, wherein each of the case histories is identified by number in the plots which corresponds to those tabulated in Table ESC-1.

the critical layers were estimated using two different $I_{c}$-FC correlations, a generic correlation proposed by Robertson and Wride (1998) and a Christchurch-soil-specific correlation developed by Robinson et al. (2013). It should be noted that Idriss and Boulanger (2008) do not recommend the use of generic $I_{c}$-FC correlations to estimate $\mathrm{FC}$, but rather recommend the development and use of project-specific $I_{c}$-FC correlations such as that developed by Robinson et al. (2013). The two correlations used in this study are shown in Figure 10. However, so as not to misclassify very loose clean sands as denser sands containing fines, an 


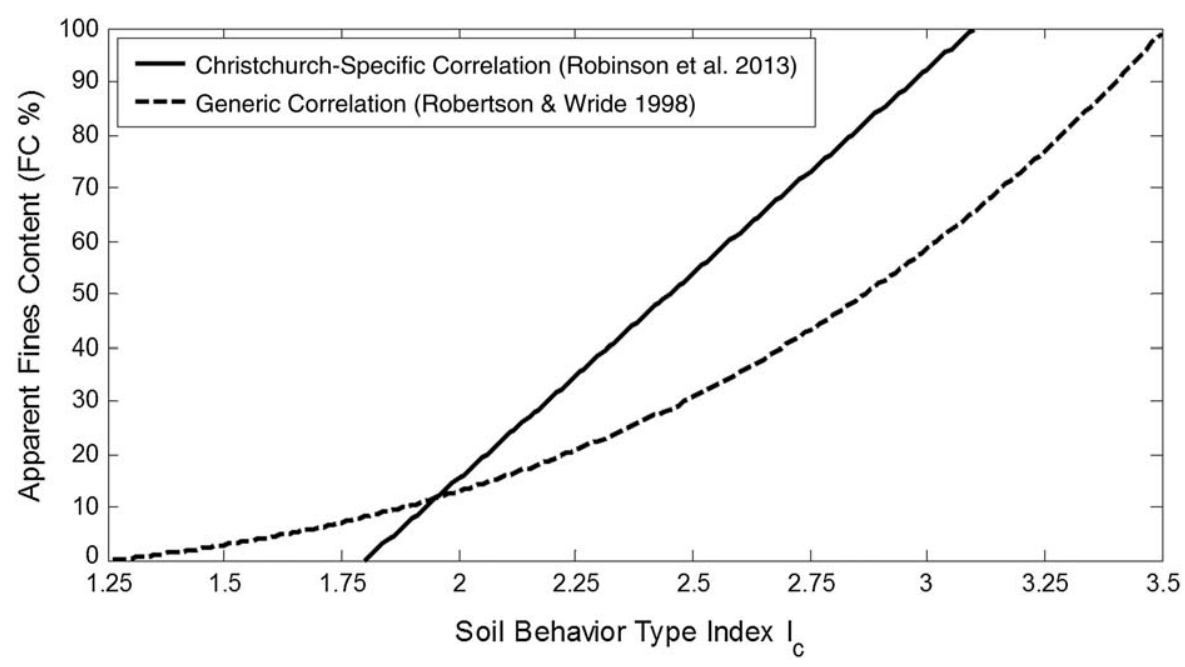

Figure 10. Correlations between $I_{c}$ and apparent FC: Christchurch-specific correlation (Robinson et al. 2013) and generic correlation (Robertson and Wride, 1998).

additional criterion was applied in estimating $\mathrm{FC}$ : $\mathrm{FC} \leq 5 \%$ if $1.64<I_{c}<2.36$ and $F<0.5 \%$, where $F$ is the normalized friction ratio and is given by (Robertson and Wride, 1998):

$$
F=\frac{f_{s}}{q_{c}-\sigma_{v}} \text { and } \sigma_{\mathrm{v}}=\text { total vertical stress }
$$

The authors computed normalized CPT tip resistances per I\&B08 for the case histories using the FC estimated using both $I_{c}$-FC correlations. The $\mathrm{CSR}_{\mathrm{M} 7.5}$ case history data for I\&B08 are plotted in Figure 9c as a function of the normalized CPT tip resistances computed using both sets of estimated FC values. In this figure, the triangular and circular symbols correspond to the normalized CPT tip resistances computed using FC values estimated using the Christchurch-soil-specific $I_{c}$-FC correlation. The "end of the tails" extending from the triangular and circular symbols correspond to the normalized CPT tip resistances computed using FC values estimated using the generic $I_{c}$-FC correlation.

As may be observed in Figure 9, several of the data points have double symbols (i.e., a circle within a circle or triangle within a triangle). These are cases where credible alternative critical layers were identified (i.e., "ambiguous" cases). However, these points are plotted for the authors' preferred critical layer, not the alternative critical layer, but similar plots showing the data plotted for the alternative critical layers are given in Part D of the Electronic Supplement.

\section{DISCUSSION}

As may be observed from Figure 9, R\&W98, MEA06, and I\&B08 correctly predicted the majority of the observed liquefaction responses for the case histories, but none of the 
procedures correctly predicted all cases. In assessing which of the three procedures gives the most accurate predictions for the data analyzed, it must be remembered that the liquefaction responses for all of the case histories presented herein are based on surface manifestations, as is the case for almost all previous liquefaction case history studies whether explicitly stated or not. As a result, a "No Liquefaction" case may mean that no stratum in the profile liquefied, or, that the severity-depth-thickness combination of a liquefied stratum was such that it did not manifest on the ground surface. On the contrary, a "Liquefaction" case (i.e., cases where surface manifestations are more severe than "Minor") can only mean that a stratum in the profile liquefied (otherwise no liquefaction surface manifestations would have occurred). Finally, a "Minor Liquefaction" case could result from a few different scenarios. For example, minor surface liquefaction manifestations could result from a relatively loose, thin, deep layer severely liquefying, from a relatively loose to medium dense, thick, shallow layer having highly elevated excess pore pressures but not necessarily liquefying, or from a relatively dense, thick, shallow layer marginally liquefying. The latter two scenarios should yield data that will constrain the position of the $\mathrm{CRR}_{\mathrm{M} 7.5}$ curve, while data from the first scenario may plot well above/to the left of the $\mathrm{CRR}_{\mathrm{M} 7.5}$ curve.

To quantitatively assess which of the three CPT-based liquefaction evaluation procedures yields the "most accurate" predictions for the data analyzed, the authors propose the following error index $\left(E_{I}\right)$ :

$$
E_{I}=\sum_{i=1}^{n} R_{i}
$$

where $n=$ number of case histories,

$$
\begin{aligned}
& R_{i}=\left\{\begin{array}{cl}
\left|\frac{C S R_{M 7.5}}{K_{\sigma}}-C R R_{M 7.5}\right| & \text { for "Liq" and "Minor Liq" cases where } \frac{C S R_{M 7.5}}{K_{\sigma}}<C R R_{M 7.5} \\
0 & \text { for "Liq" and "Minor Liq" cases where } \frac{C S R_{M 7.5}}{K_{\sigma}} \geq C R R_{M 7.5}
\end{array}\right. \\
& R_{i}=\left\{\begin{array}{cl}
\left|\frac{C S R_{M 7.5}}{K_{\sigma}}-C R R_{M 7.5}\right| & \text { for "No Liq" cases where } \frac{C S R_{M 7.5}}{K_{\sigma}}<C R R_{M 7.5} \\
0 & \text { for "No Liq" cases where } \frac{C S R_{M 7.5}}{K_{\sigma}} \leq C R R_{M 7.5}
\end{array}\right.
\end{aligned}
$$

The proposed error index will equal zero if all the predictions correctly match the field observations, but will increase in value as the number and "magnitude" of the mispredictions increases. On an individual case basis, $R$ equals zero for a correct prediction of a Liquefaction/Minor Liquefaction or No Liquefaction case, but is equal to the vertical distance between the $\mathrm{CRR}_{\mathrm{M} 7.5}$ curve and the plotted point for a mispredicted Liquefaction/ Minor Liquefaction or No Liquefaction case.

The computed $E_{I}$ values for each CPT-based liquefaction evaluation procedure are presented in Table 2. As may be observed, the I\&B08 gives the most accurate predictions of the case histories analyzed in the this paper, with the computed $E_{I}$ values for I\&B08 being relatively independent of whether the FC of the critical layers were estimated using the generic $I_{c}$-FC correlation proposed by Robertson and Wride (1998) or the Christchurch-soil-specific correlation developed by Robinson et al. (2013). The R\&W98 gives the next most accurate 
Table 2. Error indices for the three CPT-based liquefaction evaluation procedures

\begin{tabular}{lccccc}
\hline \hline & \multicolumn{5}{c}{$E_{I}$} \\
\cline { 2 - 6 } & R\&W98 & $\begin{array}{c}\text { MEA06 } \\
\left(V_{S 12} \text { dep } r_{d}\right)\end{array}$ & $\begin{array}{c}\text { MEA06 } \\
\left(V_{S 12} \text { indep } r_{d}\right)\end{array}$ & $\begin{array}{c}\text { I\&B08 } \\
\left(\text { Generic } I_{c} \text {-FC }\right. \\
\text { correlation })\end{array}$ & $\begin{array}{c}\text { I\&B08 } \\
\left(\text { Chch } I_{c} \text {-FC }\right. \\
\text { correlation })\end{array}$ \\
\hline Darfield EQ & 0.264 & 0.379 & 0.411 & 0.120 & 0.120 \\
Christchurch EQ & 0.275 & 0.225 & 0.290 & 0.047 & 0.054 \\
Total & 0.539 & 0.604 & 0.701 & 0.167 & 0.174 \\
\hline \hline
\end{tabular}

predictions of the analyzed cases from the Darfield earthquake, while the MEA06 with the $V_{S 12}$-dependent $r_{d}$ yielded more accurate predictions of the analyzed cases from the Christchurch earthquake. The least accurate predictions for the cases analyzed from both earthquakes result from the MEA06 procedure with the $V_{S 12}$-independent $r_{d}$ relation. However, the authors emphasize that the noted trends in the $E_{I}$ values are for the case histories analyzed in this study; these trends may not hold for other scenarios that are not represented by the case histories analyzed (e.g., deep/dense liquefiable layers).

The authors note that a misprediction of a Liquefaction case as a No Liquefaction case can have greater consequences than the misprediction of a No Liquefaction case as a Liquefaction case. Additionally, the authors note that minor surficial liquefaction manifestations can occur in very loose soil when excess pore pressures are elevated, even if liquefaction is not triggered (e.g., $r_{u}$ slightly less than 1.0, where $r_{u}$ is the excess pore pressure ratio). To examine the significance of a misprediction and to further distinguish Minor Liquefaction cases from Liquefaction cases, the authors present modified versions of the equations for $R_{i}$ in Part E of the Electronic Supplement. Furthermore, to determine the influence of the alternative versus the preferred critical layers on the computed $E_{I}$ values, the authors computed the $E_{I}$ values for the following scenarios: (1) authors' preferred critical layers for all cases (Table 2); (2) authors' preferred critical layers for 18 cases and alternative critical layers for the 7 "ambiguous cases"; and (3) authors' preferred critical layers for 18 cases, with the 7 "ambiguous cases" removed. As may be observed from the resulting $E_{I}$ values tabulated in Part E of the Electronic Supplement, the ranking of the three procedures remains relatively unaffected for the cases histories analyzed in this study.

Finally, as mentioned previously, it is debatable whether or not lateral spreading case histories should be included in the liquefaction triggering database due to the difficulty in their interpretation and the often lack of required field test data to properly interpret them. However, all the simplified liquefaction evaluation procedures correctly predicted the observed liquefaction response for the case histories analyzed herein where liquefaction manifested in the form of lateral spreading (i.e., Site 5: FND-01 and Site 23: Z2-6). Whether the correct prediction of these case histories is the result of judicious critical layer selection by the authors or coincidence is unknown at this time. However, further investigations are being conducted to evaluate the prediction of liquefaction triggering at sites subject to lateral spreading (e.g., Robinson et al. 2013). 


\section{SUMMARY AND CONCLUSIONS}

The combination of well-documented liquefaction responses during multiple events, densely recorded ground motions for the events, and detailed subsurface characterization in relation to the 2010-2011 Canterbury, New Zealand, earthquake sequence provides an unprecedented opportunity to add quality case histories to the liquefaction database. Toward this end, this paper presents 50 high-quality CPT liquefaction case histories stemming from 25 sites selected by the authors and analyzed for two earthquakes. The majority of the sites selected liquefied during the Darfield earthquake and either had no or only minor surficial liquefaction manifestations resulting from the Christchurch earthquake, or vice versa. Additionally, all sites were located relatively close to strong ground motion stations and were characterized by both CPT soundings and surface wave testing. The guiding principle in selecting the critical layers for the case histories was that the depth-thickness-density combination of the critical layer for a given site be consistent with the observed liquefaction response of the site. The case histories were used to evaluate three deterministic, CPTbased simplified liquefaction evaluation procedures that are in common use: R\&W98, MEA06, and I\&B08. Although all of the procedures accurately predicted the majority of the case histories correctly, I\&B08 resulted in the lowest error index for the 50 case histories analyzed, with lower $E_{I}$ values indicating better predictions of the observed liquefaction response. However, the noted trends in the $E_{I}$ values for the case histories analyzed in this study may not hold for other scenarios (e.g., deep/dense liquefiable layers) that are not represented by the case histories presented in this study.

\section{ACKNOWLEDGMENTS}

The authors gratefully acknowledge the Canterbury Geotechnical Database and the New Zealand GeoNet project and its sponsors EQC, GNS Science, and LINZ, for providing some of the data used in this study. Also, the authors are grateful to Dr. Josh Zupan and Dr. Jonathan Bray who oversaw the performance of some of the CPT soundings presented in this study (Bray et al. 2014), to Mr. Kevin Foster for performing SEM and EDS analyses on liquefaction ejecta samples, and to Dr. Matthew Hughes for computing the grade at the case history sites. Additionally, the authors thank Drs. Robb Moss and Ross Boulanger for answering questions and providing information about the MEA06 and I\&B08 liquefaction evaluation procedures, respectively. The primary support for the US authors was provided by U.S. National Science Foundation (NSF) grants CMMI-1030564, CMMI-1137977, and CMMI-1306261. Also, L. Wotherspoon's position at the University of Auckland is funded by the Earthquake Commission (EQC). However, any opinions, findings, and conclusions or recommendations expressed in this material are those of the authors and do not necessarily reflect the views of the National Science Foundation or the other funding agencies.

\section{REFERENCES}

Abrahamson, N. A., and Youngs, R. R., 1992. A stable algorithm for regression analyses using the random effects model, Bulletin of the Seismological Society of America 82, 505-510.

ASTM International (ASTM), 2011. D2487-11 Standard Practice for Classification of Soils for Engineering Purposes (Unified Soil Classification System), West Conshohocken, PA. 
Bradley, B. A., 2010. NZ-specific Pseudo-spectral Acceleration Ground Motion Prediction Equations Based on Foreign Models, Department of Civil and Natural Resources Engineering, University of Canterbury, Christchurch, NZ, 324 pp.

Bradley, B. A., 2012a. Strong ground motion characteristics observed in the 4 September 2010 Darfield, New Zealand, earthquake, Soil Dynamics and Earthquake Engineering 42, $32-46$.

Bradley, B.A., 2012b. Ground motions observed in the Darfield and Christchurch earthquakes and the importance of local site response effects, New Zealand Journal of Geology and Geophysics 55, 279-286.

Bradley, B. A., 2013a. Estimation of site-specific and spatially-distributed ground motion in the Christchurch earthquakes: Application to liquefaction evaluation and ground motion selection for post-event investigation, in Proc. 19th New Zealand Geotechnical Symposium, 20-23 November 2013, Queenstown, NZ, 8 pp.

Bradley, B. A., 2013b. A New Zealand-specific pseudo-spectral acceleration ground-motion prediction equation for active shallow crustal earthquakes based on foreign models, Bulletin of the Seismological Society of America 103, 1801-1822.

Bradley, B. A., and Cubrinovski, M., 2011. Near-source strong ground motions observed in the 22 February 2011 Christchurch Earthquake, Seismological Research Letters 82, $853-865$.

Bradley, B. A., Quigley, M. C., Van Dissen, R. J., and Litchfield, N. J., 2014. Ground motion and seismic source aspects of the Canterbury earthquake sequence, Earthquake Spectra 30, $1-15$.

Bray, J., Cubrinovski, M., Bradley, B. A., and Taylor, M., 2014. Liquefaction effects on buildings in the Central Business District of Christchurch, Earthquake Spectra 30, 85-109.

Brown, L. J., Beetham, R. D., Paterson, B. R., and Weeber, J. H., 1995. Geology of Christchurch, New Zealand, Environmental and Engineering Geoscience 1, 427-488.

Cetin, K. O., 2000. Reliability-Based Assessment of Seismic Soil Liquefaction Initiation Hazard, Ph.D. Thesis, University of California, Berkeley.

Cousins, J., and McVerry, G., 2010. Overview of strong motion data from the Darfield earthquake, Bulletin of the New Zealand Society for Earthquake Engineering 43, 222-227.

Cox, B., and Wood, C., 2011. Surface Wave Benchmarking Exercise: Methodologies, Results and Uncertainties, GeoRisk 2011: Geotechnical Risk Assessment and Management (C. H. Juang et al., eds.), ASCE Geotechnical Special Publications (GSP) 224, Reston, VA.

Cubrinovski, M., and Green, R. A. (Editors), 2010. Geotechnical reconnaissance of the 2010 Darfield (Canterbury) Earthquake, (contributing authors in alphabetical order: J. Allen, S. Ashford, B. Bowman, B. Bradley, B. Cox, M. Cubrinovski, R. Green, T. Hutchinson, E. Kavazanjian, R. Orense, M. Pender, M. Quigley, L. Wotherspoon), Bulletin of the New Zealand Society for Earthquake Engineering 43, 243-320.

Cubrinovski, M., Bradley, B., Wotherspoon, L., Green, R., Bray, J., Woods, C., Pender, M., Allen, J., Bradshaw, A., Rix, G., Taylor, M., Robinson, K., Henderson, D., Giorgini, S., Ma, K., Winkley, A., Zupan, J., O’Rourke, T., DePascale, G., and Wells, D., 2011. Geotechnical aspects of the 22 February 2011 Christchurch earthquake, Bulletin of the New Zealand Society for Earthquake Engineering 44, 205-226.

Cubrinovski, M., Robinson, K., Taylor, M., Hughes, M. M., and Orense, R., 2012. Lateral spreading and its impacts in urban areas in the 2010-2011 Christchurch earthquakes, New Zealand Journal of Geology and Geophysics 55, 255-269. 
Forsyth, P., Barrell, D., and Jongens, R., 2008. Geology of the Christchurch Area, Institute of Geological and Nuclear Sciences GNS Science 1:250,000 Geological Map 16, 67 pp.

GeoNet, 2012. Quake Search, available at http://magma.geonet.org.nz/resources/quakesearch/ (last accessed 26 Nov 2012).

Goda, K., and Hong, H. P., 2008. Spatial correlation of peak ground motions and response spectra, Bulletin of the Seismological Society of America 98, 354-465.

Green, R. A., Allen, A., Wotherspoon, L., Cubrinovski, M., Bradley, B., Bradshaw, A., Cox, B., and Algie, T., 2011. Performance of levees (stopbanks) during the 4 September $\mathrm{M}_{\mathrm{w}} 7.1$ Darfield and 22 February $2011 \mathrm{M}_{\mathrm{w}} 6.2$ Christchurch, New Zealand, earthquakes, Seismological Research Letters 82, 939-949.

Green, R. A., Obermeier, S. F., and Olson, S. M., 2005. Engineering geologic and geotechnical analysis of paleoseismic shaking using liquefaction effects: Field examples, Engineering Geology 76, 263-293.

Green, R. A., Wood, C., Cox, B., Cubrinovski, M., Wotherspoon, L., Bradley, B., Algie, T., Allen, J., Bradshaw, A., and Rix, G., 2011. Use of DCP and SASW tests to evaluate liquefaction potential: Predictions vs. observations during the recent New Zealand earthquakes, Seismological Research Letters 82, 927-938.

Idriss, I. M., and Boulanger, R.W., 2008. Soil liquefaction during earthquakes. Monograph MNO-12, Earthquake Engineering Research Institute, Oakland, CA, 261 pp.

Idriss, I. M., and Boulanger, R. W., 2012. Examination of SPT-based liquefaction triggering correlations, Earthquake Spectra 28, 989-1018.

Johnson, R. A., and Wichern, D. W., 2007. Applied Multivariate Statistical Analysis, Prentice Hall, Upper Saddle River, NJ

Maurer, B. W., Green, R. A., Cubrinovski, M., and Bradley, B. A., 2014. Evaluation of Liquefaction Potential Index (LPI) for Assessing Liquefaction Hazard: Case Study Christchurch, New Zealand, Journal of Geotechnical and Geoenvironmental Engineering, ASCE, in press.

Moss, R. E. S, Seed, R. B., Kayen, R. E., Stewart, J. P., Der Kiureghian, A., and Cetin, K. O., 2006. CPT-based probabilistic and deterministic assessment of in situ seismic soil liquefaction potential, Journal of Geotechnical and Geoenvironmental Engineering, ASCE, 132, 1032-1051.

Olson, S. M., Green, R. A., and Obermeier, S. F., 2005. Engineering geologic and geotechnical analysis of paleoseismic shaking using liquefaction effects: A major updating, Engineering Geology 76, 235-261.

Orense, R. P., Kiyota, T., Yamada, S., Cubrinovski, M., Hosono, Y., Okamura, M., and Yasuda, S., 2011. Comparison of liquefaction features observed during the 2010 and 2011 Canterbury earthquakes, Seismological Research Letters 82, 905-918.

Pinheiro, J., Bates, D. M., DebRoy, S.Sarkar, D., and the R Core Team, 2008. nlme: Linear and Nonlinear Mixed Effects Models, R package version 3.1, 89 pp.

Quigley, M. C., Bastin, S., and Bradley, B. A., 2013. Recurrent liquefaction in Christchurch, New Zealand, during the Canterbury earthquake sequence, Geology 41, 419-422.

Robertson, P. K., 2009. Performance based earthquake design using the CPT, in Performance Based Design in Earthquake Geotechnical Engineering: From Case History to Practice (T. Kokusho, Y. Tsukamoto, and M. Yoshimine, eds.), Taylor \& Francis Group, London, $3-20$. 
Robertson, P. K., and Cabal, K. L., 2010. Estimating soil unit weight from CPT, 2nd International Symposium on Cone Penetration Testing, Paper \#2-40, May 2010, Huntington Beach, CA.

Robertson, P. K., and Cabal, K. L., 2012. Guide to Cone Penetration Testing for Geotechnical Engineering, $5^{\text {th }}$ edition, Gregg Drilling \& Testing, $131 \mathrm{pp}$.

Robertson, P. K., and Wride, C. E., 1998. Evaluating cyclic liquefaction potential using the cone penetration test, Canadian Geotechnical Journal 35, 442-459.

Robinson, K., Cubrinovski, M., and Bradley, B. A., 2013. Sensitivity of predicted liquefactioninduced lateral displacements from the 2010 Darfield and 2011 Christchurch earthquakes, in Proc. 2013 Conference of the New Zealand Society for Earthquake Engineering (NZSEE 2013), 26-28 April, Wellington, New Zealand.

Whitman, R. V., 1971. Resistance of soil to liquefaction and settlement, Soils and Foundations 11, 59-68.

Wood, C. M., Cox, B. R., Wotherspoon, L. M., and Green, R. A., 2011. Dynamic site characterization of Christchurch strong motion stations, Bulletin of the New Zealand Society for Earthquake Engineering 44, 195-204.

Wotherspoon, L. M., Pender, M. J., and Orense, R. P., 2012. Relationship between observed liquefaction at Kaiapoi following the 2010 Darfield earthquake and former channels of the Waimakariri River, Engineering Geology 125, 45-55.

Youd, T. L., Idriss, I. M., Andrus, R. D., Arango, I., Castro, G., Christian, J. T., Dobry, R., Finn, W. D. L., Harder, L. F., Hynes, M. E., Ishihara, K., Koester, J. P., Liao, S. S. C., Marcuson, III, W. F., Martin, G. R., Mitchell, J. K., Moriwaki, Y., Power, M. S., Robertson, P. K., Seed, R. B., and Stokoe, II, K. H., 2001. Liquefaction resistance of soils: Summary report from the 1996 NCEER and 1998 NCEER/NSF workshops on evaluation of liquefaction resistance of Soils, Journal of Geotechnical and Geoenvironmental Engineering 127, 297-313.

Zywicki, D.J., 1999. Advanced signal processing methods applied to engineering analysis of seismic surface waves, Ph.D. Thesis, Georgia Institute of Technology, Atlanta, GA, 357 pp.

(Received 5 March 2013; accepted 27 August 2013) 